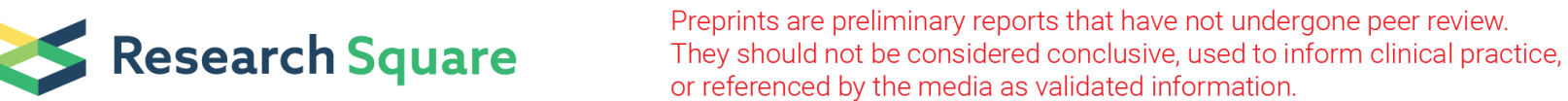

\section{The Saliva Cortisol and Amylase Levels Related With Stress Response Compared by Different Analytical Methods}

Rabia Şemsi ( $\sim$ rabiasemsi2010@gmail.com )

Gazi University Faculty of Medicine: Gazi Universitesi Tip Fakultesi https://orcid.org/0000-0002-84775537

Umut Kökbaş

University of Kyrenia: Girne Universitesi

Burak Arslan

Gazi University Faculty of Medicine: Gazi Universitesi Tip Fakultesi

Aylin Sepici Dinçel

Gazi University Faculty of Medicine: Gazi Universitesi Tip Fakultesi

\section{Erdal Ergünol}

Cyprus International University: Uluslararasi Kibris Universitesi

\section{Levent Kayrin}

University of Kyrenia: Girne Universitesi

\section{Research Article}

Keywords: Saliva, Cortisol, Amylase, Biosensor, Stress, Method Comparison

Posted Date: May 5th, 2021

DOl: https://doi.org/10.21203/rs.3.rs-459081/v1

License: (c) (i) This work is licensed under a Creative Commons Attribution 4.0 International License.

Read Full License

Version of Record: A version of this preprint was published at Applied Biochemistry and Biotechnology on October 8th, 2021. See the published version at https://doi.org/10.1007/s12010-021-03676-9. 


\section{Abstract}

Sampling of salivary cortisol and salivary amylase is non-invasive and important for the evaluation of the hypothalamic-pituitar-adrenal axis funciton and stress levels. This study aims to compare the values of the cortisol and salivary amylase measured by using three diffeent analytical methods and discuss the comparison of stress levels of samples.Young adults $(n=23)$ saliva samples were collected between 08.00 and 09.00 am, noon at 12.00 (before exam) and 14.00-15.00 (after unaware exam) during the first 48 hours, no freezing / thawing was done. Salivary cortisol and salivary amylase levels in subjects were measured by three different analytical methods (ELISA, Chemiluminescence and Biosensor).Comparison of method between ELISA and biosensor in determining salivary kortizol levels showed a good correlation $y=2.971+0.748 x\left(R^{2}=0.839\right)$. Salivary amylase concentrations were found only by ELISA method.The detection/information effectiveness as compared with conventional determination method ELISA, considering the low cost, fast results and specificity characteristics biosensor can be offered as an alternative method.

\section{Highlights}

Saliva is an easy and non-invasive alternative body fluid which will represent health status as blood samples, however method comparisons are necessary to speculate on the accuracy of worked biochemical parameters.

Biosensor methods could be a point of care tests, easy and cheap, related with the logic of biosensor methods, strip tests for saliva might be developed.

The relevancy to saliva samples increases, besides routine biochemical parameters as we are working on liquid biopsy, cell free DNA sampling for specific diseases will improve scientific rationale and explain mechanisms of diseases.

Saliva can work as a diagnostic tool.

\section{Introduction}

Saliva samples can be used as a non-invasive monitoring tool for stress analysis by measuring the cortisol levels which is one of the biomarker of stress in addition to salivary enzyme, a-amylase and glucocorticoids $[1,2,3]$.Recently, saliva samples have been prefered instead of blood samples as the salivary cortisol levels correlate to the cortisol levels in serum samples. Since unbound cortisol has biologically active, it is more useful to determine the cortisol level in saliva $[4,5,6]$.

Saliva cortisol, measured by traditional methods, is in free form and delivered directly to the target tissues along the capillaries. The saliva level of cortisol reliably reflects hypothalamus-pituitary-adrenal (HPA) axis activity and has been used in many studies as a biological stress marker [7]. 
Saliva a-amylase enzyme, that is produced by the salivary glands, released as a result of activation of the autonomic nervous system and breaks down the starch [8]. Both physiological and psychological stressors are used to demonstrate the relationship between saliva a-amylase enzyme and stress. However, despite the existence of many studies explaining this relationship, contradictory results are encountered [9]. Saliva a-amylase enzyme is also used as an indicator in non-invasive measurement of stress and these measurements generally use the substrate method (CNPG3) [10].

Enzyme-linked immunosorbent assay or autoanalyser was used in many studies of salivary cortisol and amylase levels. However, immunoassay accuracy and precision may be reduced due to interacting effects, such as matrix effects of sample constituents on the antigen-antibody interaction, potentially also restricted analytical range [11]. Successful measurement of cortisol (steroids) relies upon using a very sensitive and specific method of analysis. Analysis of steroids by biosensor has previously been shown to be superior to immunoassay, in terms of both increased specificity and sensitivity $[12,13]$.

While a-amylase and cortisol can be measured by different methods, no studies comparing them with each other have been found. Therefore, in this study, three methods that measure a-amylase enzyme activity and cortisol levels with different methods discussed and their cost, duration and practicality features were compared. In addition, data on these methods was evaluated in terms of their relationship with stress in young adult individuals.

\section{Materials And Methods}

\section{Collection of Saliva Samples}

Saliva samples were collected using an oral swab (SARSTEDT brand Salivette oral swab) made of polypropylene/low density polyethylene (LD-PE) material designed specifically for cortisol. These tubes provide high analytical results from small quantities of samples.

In order to keep the standardization related with circadian rhythms saliva samples were collected between 8-9 am. Nevertheless, it was convened 12 am (pre-stress) and between 2-3 pm (post-stress/after unaware exam hour) to evaluate its relationship with stress. Within 60 minutes before the test, individuals were not allowed to smoke, eat, drink liquids or brush their teeth They were asked to soak the swab with saliva for 1 or 2 minutes until they are saturated completely. Tubes were waited 30 minutes at room temperature and then centrifuged for 10-15 minutes at approximately $3200 \mathrm{~g}$. After centrifugation, the swab and small insert were thrown away, and the large outer tube was stored at $-80^{\circ} \mathrm{C}$ until analysis.

The twenty-three healthy young adult of faculty of dentistry students were recruited to the study. Exclusion criteria were presence of any disease that can affect hypothalamic-pituitary-adrenal (HPA) axis.

\section{Analysis methods}


We divided saliva samples into 3 sets: the first set was for ELISA kit, second set was for biosensor and the other set was for chemiluminescence immunoassay.

\section{Elisa}

Salivary cortisol and salivary amylase was measured by using a high-sensitivity ELISA kit (DiametraImmunodiagnostic System; Lot:4817A; USCN SEB482Hu Enzyme-Linked Immunoabsorbent Assay Kit, for Amylase Alpha 1, Salivary (AMY1) Lot:L181030297), according to the manufacturer's instructions, respectively.

\section{Biosensor}

In the current study, a previously optimized method is used in the biosensor prepared for cortisol and amylase.

\section{Sensor fabrication}

The cortisol and amylase sensor has three electrode system consists of a nanopolymer modified gold working electrode, reference electrode and counter electrode. Bioactive layer of the poly aniline nanopolymer modified gold working electrode has also anti-cortisol and anti-amylase antibody on its surface, because the biosensor system's working principle is depending on a specific interaction between antigen and antibody of cortisol and amylase. When antigen-antibody interaction occurs a potential differentiation detection with bioelectrochemical methods happens.

Differential pulse spectroscopy and cyclic voltammetry was used to characterize electrical performance of the fabricated sensor system and identify the electrical nature of molecules used in each step of the immunoassay.

Poly aniline conducting nanopolymer (Sigma, USA) was used to bioactive layer component for surface expansion. The electrodes were immersed on aniline solution for electrochemical polymerisation. Whereas a capture antibody specific to cortisol was used for the detection of cortisol in buffer solutions which were the immunoassay reagents of the salivary cortisol ELISA kit, a capture antibody specific to amylase was used for the detection of amylase in buffer solutions which were the immunoassay reagents of the salivary amylase ELISA kit.

Electrochemical differential pulse spectroscopy has used for characterization of binding events on surface of sensors of working electrodes. In our method, we used an electrochemical differential pulse spectroscopy to characterize the binding of the different entities on the electrode surface as they create a coulombic potential, which could be screened as differential pulse changes. Electrical double layer capacitance is reflective of the columbic potentials developed due to biomolecular binding. Experimental parameters used in this study included Vrms=10 mV and frequency range of $10 \mathrm{~Hz}$ to $10 \mathrm{kHz}[14,15]$.

\section{Calibration of sensor platform for detection}


Prior to test the human salivary cortisol and salivary amylase samples, the sensor was first calibrated by calibration standards in PBS buffer. The target antigen was calibrated for signal changes occurring due to; binding cortisol and amylase antigen with capture antibody probes on the sensing electrodes and binding of detection antibody to antigen-capture antibody conjugate on the sensing electrodes. The calibration response was performed for a total of $n=10$ replicates and error were calculated as the SD over mean. Curve fitting was performed to establish a correlation between varying concentrations of the calibration standards with respect to differential pulse measured. As a negative control, each of the sensor arms was also tested for nonspecific signal with the blank buffer solution and cortisol and amylase from healthy volunteers.

\section{Detection of human salivary cortisol and salivary amylase samples}

The sensor platform was tested for feasibility and accuracy of detection of cortisol and amylase at human salivary to show proof of feasibility for detection using differential pulse spectroscopy toward application in companion diagnostics. A total of 23 samples were tested and a semi quantitative analysis was used to compare with results obtained from ELISA. The samples were not diluted because wide detection range of the designed sensor. The samples were added at a volume of $20 \mu \mathrm{L}$ to the sensors working cell. The sample was incubated for $1 \mathrm{~min}$. Differential pulse measurements were performed without the need for any wash steps.

\section{Chemiluminescence Immunoassay}

The other set of saliva samples were used to measure cortisol and amylase levels in saliva using cortisol and amylase testing as in serum and plasma samples. Saliva samples were transferred to the sample cups and measured by the Beckman Coulter DxL 800 autoanalyzer.

\section{Statistical analysis}

Statistical analysis was performed using SPSS 18 statistics program, Jamovi and Analyse-it programs. The means and standard deviations of the samples were taken in all applied methods. To determine whether the distribution of data was normal, the Shapiro-Wilk test was used. Since the data were distributed homogenously, statistical analysis was done by parametric tests. The results are presented as mean and standard deviation levels. Comparisons between the groups of data were evaluated by use of parametric One -Way Anova and the Tukey Post-Hoc tests. Spearman's correlation coefficient was calculated to assess the strength and direction of the compared data. The results were evaluated with a confidence interval of $95 \%$ and statistical significance was set at a p-value of less than 0.05 . Linear regression was carried out Passing-Bablok regression. Regression analysis of Enzyme-Linked Immunoabsorbent Assay (ELISA), chemiluminescence immunoassay (autoanalyzer) and biosensor data obtained in the method comparison study were performed. Different between methods were evaluated by calculating bias and limits of agreement using Bland-Altman charts.

\section{Results And Discussion}


Many researchers working in different fields use stress measurement in saliva samples. It needs an optimal method when evaluating stress-related parameters. At the same time, saliva samples should be collected and administered simultaneously. The most commonly used saliva stress markers are cortisol and amylase.

In the current study, a biosensor was used to determine the amounts of cortisol and a-amylase in saliva. The level of compatibility and comparison of other measurement methods used with reference to the new measurement method were examined using statistical analysis methods. In a second step, it was discussed whether there is a difference in saliva cortisol and amylase levels during stress.

In 23 healthy young adults (17 female and 6.male), the mean age was $20.5 \pm 0.95$ years (range:20-24 years). The mean age in the female and male groups were $20.2 \pm 0.43$ and $21.17 \pm 1,60(p=0.001)$ respectively. The mean and standard deviations of cortisol and amylase concentrations obtained in salivary samples taken in the morning, pre-stress and post-stress are shown in Table 1.

As a result of the studies conducted in young adults, who can use all three methods in case of stress, it was determined that there are differences in cortisol concentrations. It was observed that the cortisol level in the saliva taken in the morning hours was high, it decreased pre-stress, and the salivary cortisol levels increased post stress. It was observed that the salivary amylase concentration was decreased in the morning hours and increased before and after stress.

The performance of the methods used in determining the levels of cortisol and alpha-amylase were examined in 3 different times in the morning, pre-stress and post-stress in young adult individuals. In Figure 1, the findings of ELISA, biosensor and autoanalyzer methods for the young adult individuals examined in the study are presented.

While each method reveals salivary cortisol concentrations close to each other in all three times, salivary amylase concentrations were found only in the ELISA method (Table I). In ELISA and Biosensor method, post-stress salivary cortisol levels were found to be higher than pre-stress. In the autoanalyzer method, cortisol levels were found to be higher in the morning saliva samples than pre and post-stress (Table 1). Details of post-hoc analysis for comparative analysis of different methods between different study groups are given in Table 2.

When we pooled all the salivary samples of the subjects into 3 methods, 69 samples were obtained for each method. The relationship between methods tested by Spearman's rho correlation analysis. There were significant positive correlations between ELISA and Biosensor levels ( $\left.r=0.965^{\star \star} ; p=0.0005\right)$ (Figure 2).

In the evaluation of salivary cortisol levels, the correlation measured with the cortisol biosensor is in good agreement with the measurements made by the traditional ELISA method. On the other hand, cortisol biosensor values appear to be slightly higher than the cortisol ELISA. The difference is that, firstly, the 
biosensor has higher sensitivity than ELISA. Secondly, the current reduction caused by impurities increases the biosensor results because the current is inversely proportional to the solution concentration.

Saliva cortisol measurement results obtained by three methods were evaluated statistically. Regression analysis was carried out to examine the relationship between them and this relationship was expressed as the correlation coefficient. The values obtained from all three measurement systems were evaluated by Spearman correlation analysis and a significant difference was found between the three methods.

The distribution of cortisol results between ELISA method and Autoanalyzer method is as shown in Figure 3. Regression analysis for these two methods; $R^{2}=0.012, a=6.2378 b=0.0811$. When we put the equation of the curve in the equation $y=a+b x, y=6.238+0.0811 x$ was found. It was proved that the results of ELISA method and autoanalyser method were statistically different. $(r=0.109 ; p=0.374)$.

The present data showed for the mean concentration of salivary cortisol measured autoanalyzer was significantly different from that measured by ELISA.

The distribution of cortisol results between ELISA method and biosensor method is as shown in Figure 4 . As a result of the regression analysis for these two methods, $R^{2}=0.839, a=2.971, b=0.748$. When we put the equation of the curve in the equation $y=a+b x, y=2.971+0.748 x$ was found. It was proved that ELISA method and biosensor method results were not statistically different $(r=0.916 ; p=0.0007)$.

When we compared the reference method Biosensor method with other methods, it was determined that the results of the ELISA method were similar to the Biosensor, but it was determined that they were different with the other method, Chemiluminescence immunoassay.

The distribution of cortisol results between Autoanalyzer method and Biosensor method is as shown in Figure 5. Regression analysis for these two methods; $R^{2}=0.019, a=9.983, b=0.153$ When we put the equation of the curve in the equation $y=a+b x, y=9.983+0.153 x$ was found. It was proved that the results of the autoanalyser method and biosensor method were statistically different $(r=0.138 ; p=0.264)$.

Saliva a-amylase levels could not be determined in autoanalyzer and biosensor. The biosensor method developed is not suitable for determining the level of amylase. It was observed that the correct measurement range of the ELISA kit used for amylase was narrow and there was no reproducibility in the study with the saliva sample. We think that this is due to the lack of method validation for saliva samples, although the kit is compatible with all body fluids.

As a result of the studies conducted, it was seen that the biosensor method developed for cortisol is an alternative method due to low cost, fast result, specificity and high detection / information efficiency compared to ELISA.

\section{Conclusions}


Although saliva collection and analysis show some drawbacks, with increasing analysis advances and technological advances, it has been recognized as an attractive diagnostic fluid for the detection of various saliva biomarkers.

The acceptance of any new methodological approach to assessment of cortisol and a-amylase in a given research environment depends on the ease of saliva sampling, the storage conditions and the reliability of available assays for analysis. Given that these characteristics, the cost of the new technique should be advantageous over other conventional methods.

Biosensors, which are the laboratory technology of the 21 st century, draw intense attention due to their advantages compared to classical methods [14-15]. In the current study, a new biosensor was designed to determine saliva cortisol amounts. In line with the obtained results, the biosensor method has been demonstrated to be applicable. It is thought that the biosensor method can offer saliva cortisol levels as an alternative analytical method with low cost, fast results, high perception and information validity compared to chemiluminescence immunoassay and ELISA methods.

\section{Declarations}

Ethical Approval : Our study was performed with the approval of the ethics review board of the Gazi University Faculty of Medicine Ethics Committee and all the participants gave written informed consent. The number of the ethical approval is 831-12.11.2018

Informed Consent: Written consent was obtained from the participants.

Consent to Publish: Not applicable

Peer Review: Externally peer-reviewed

Author Contribution: Conception/Design of Study-R.Ş., E.E., A.S.D.; Data Acquisition- R.Ş., A.S.D.; Data Analysis/Interpretation-R.Ş., U.K., B.A; Drafting Manuscript- R.Ş., U.K., A.S.D. ; Critical Revision of Manuscript- E.E., A.S.D. L.K.; Final Approval and Accountability- R.Ş., A.S.D. L.K.

Declaration of interest: The authors report no conflicts of interest. The authors alone are responsible for the content and writing of the paper.

Financial \& competing interests disclosure: This work was supported by the Gazi University, Projects of Scientific Investigation (BAP) (No.01/2019-07), Turkey. The authors have no other relevant affiliations or financial involvement with any organization or entity with a financial interest in or financial conflict with the subject matter or materials discussed in the manuscript apart from those disclosed.

Availability of data and materials: Not applicable 


\section{References}

1. Skosnik PD, Chatterton RT, Swisher T, Park S. (2000). Modulation of attentional inhibition by norepinephrine and cortisol after psychological stress. Int J Psychophysiol, 36(1):59-68.

2. Booij SH, Bos EH, Bouwmans ME, van Faassen M, Kema IP, Oldehinkel AJ, de Jonge P. (2015). Cortisol and a-amylase secretion patterns between and within depressed and nondepressed individuals. PLoS One, 10(7): e0131002.

3. Petrakova L, Doering BK, Vits S, Engler H, Rief W, Schedlo.wski M, Grigoleit JS. (2015). Psychosocial stress increases salivary alpha-amylase activity independently from plasma noradrenaline levels. PLoS One, 10(8): e0134561.

4. Hofmann LF. (2001).Human saliva as a diagnostic specimen.J Nutr,131(5):1621S-5S.

5. Obayashi K. (2013). Salivary mental stress proteins. Clin Chim Acta, 425:196-201.

6. Nater UM, Rohleder N, Gaab J, Berger S, Jud A, Kirschbaum C, Ehlert U. (2005). Human salivary alpha-amylase reactivity in a psychosocial stress paradigm. Int J Psychophysiol, 55(3): 333-42

7. Groer M, Murphy R, Bunnell W, Salomon K, Van Eepoel J, Rankin B, et al. (2010).Salivary measures of stress and immunity in police officers engaged in simulated critical incident scenarios. $J$ Occup Environ Med.52:595-602.

8. Allwood MA, Handwerger K, Kivlighan KT, Granger D A, Stroud LR. (2011). Direct and moderating links of salivary alpha-amylase and cortisol stress-reactivity to youth behavioral and emotional adjustment.Biol Psychol, 88(1): 57-64.

9. Kang Y. (2010). Psychological stress-induced changes in salivary alpha-amylase and adrenergic activity.Nurs Health Sci 12(4): 477-84.

10. Rohleder N, Wolf JM, Maldonado EF, Kirschbaum C. (2006). The psychosocial stress-induced increase in salivary alpha-amylase is independent of saliva flow rate. Psychophysiol, 43(6): 645-52.

11. Ceglarek U, Werner M, Kortz L, Körner A, Kiess W, Thiery J, Kratzsch J. (2010). Preclinical challenges in steroid analysis of human samples. J Steroid Biochem Mol Biol,121:505-12.

12. S. Lee, (2012). Essential oil inhalation on blood pressure and salivary cortisol levels in prehypertensive and hypertensive subjects, Evidence-Based Complementary and Alternative Medicine, vol. , Article ID 984203, 9 pages.

13. M. Castro, P. C. L. Elias, C. E. Martinelli Jr., S. R. R. Antonini, L. Santiago, and A. C. Moreira (2000). Salivary cortisol as a tool for physiological studies and diagnostic strategies,Brazilian Journal of Medical and Biological Research, vol. 33, no. 10, pp. 1171-1175.

14. Kokbas U., Kayrın L., Tuli A. (2013). Biosensors and their medical applications. Arch Med Rev J, 23:499-513.

15. Dündar Yenilmez E., Kökbaş U., Kartlaşmış K., Kayın L., Tuli A. (2018). A new biosensor for noninvasive determination of fetal RHD status in maternal blood of RhD negative pregnant women. PLOS ONE, Jun 6, 13:(6): e0197855. 


\section{Tables}

Table 1The mean and standard deviation salivary cortisol and salivary amylase levels, obtained using different biochemical analytical methods at different sampling of times

\begin{tabular}{|llll|}
\hline Time of sampling & $\begin{array}{l}\text { Morning (08:00-09:00 } \\
\mathrm{am})\end{array}$ & $\begin{array}{l}\text { Pre-stress (12:00 } \\
\mathrm{am})\end{array}$ & $\begin{array}{l}\text { Post-stress (14:00- } \\
\mathbf{1 5}: 00)\end{array}$ \\
\hline SC-ELISA $(\mu \mathrm{g} / \mathrm{dL})$ & $10.76 \pm 3.30$ & $8.64 \pm 3.33$ & $12.67 \pm 5.96$ \\
\hline SC-Biosensor $(\mu \mathrm{g} / \mathrm{dL})$ & $12.12 \pm 7.23$ & $9.47 \pm 3.65$ & $12.63 \pm 3.61$ \\
\hline $\begin{array}{l}\text { SC-Autoanlayser } \\
(\mu \mathrm{g} / \mathrm{dL})\end{array}$ & $9.66 \pm 2.93$ & $5.76 \pm 2.54$ & $7.13 \pm 2.06$ \\
\hline sAA-ELISA $(\mathrm{ng} / \mathrm{mL})$ & $17.92 \pm 4.21$ & $30.65 \pm 9.74$ & $117.52 \pm 38.1$ \\
\hline
\end{tabular}

Table 2 Post-hoc analysis for comparative analysis of different analytical methods of measurement for cortisol levels between study groups

\begin{tabular}{|c|c|c|c|c|}
\hline $\begin{array}{l}\text { Methods of measurement for Salivary } \\
\text { Cortisol }(\mu \mathrm{g} / \mathrm{dL})\end{array}$ & Study Groups & Morning & $\begin{array}{l}\text { Pre- } \\
\text { Stress }\end{array}$ & $\begin{array}{l}\text { Post- } \\
\text { stress }\end{array}$ \\
\hline \multirow[t]{4}{*}{ ELISA } & $\begin{array}{l}\text { Morning (08:00- } \\
09: 00 \text { am) }\end{array}$ & - & 0.235 & 0.308 \\
\hline & & 0.235 & - & \multirow{2}{*}{$\begin{array}{l}0.007 * \star \\
-\end{array}$} \\
\hline & $\begin{array}{l}\text { Pre-Stress }(12: 00 \\
\text { am) }\end{array}$ & 0.308 & $0.007^{\star \star}$ & \\
\hline & $\begin{array}{l}\text { Post-Stress (14:00- } \\
\text { 15:00 pm) }\end{array}$ & & & \\
\hline \multirow[t]{4}{*}{ Autoanalyzer } & $\begin{array}{l}\text { Morning (08:00- } \\
09 \cdot 00 \text { am) }\end{array}$ & - & $0.0009 * * *$ & $0.0001 * * *$ \\
\hline & & \multirow{3}{*}{$\begin{array}{l}0.0009^{* * *} \\
0.0001^{* * *}\end{array}$} & - & \multirow{2}{*}{$\begin{array}{l}0.996 \\
-\end{array}$} \\
\hline & am) & & 0.996 & \\
\hline & $\begin{array}{l}\text { Post-Stress }(14: 00- \\
\text { 15:00 pm) }\end{array}$ & & & \\
\hline \multirow[t]{4}{*}{.Biosensor } & $\begin{array}{l}\text { Morning (08:00- } \\
\text { 09:00 am) }\end{array}$ & - & 0.329 & 0.260 \\
\hline & Pre-Stress (12.0n & 0.329 & - & \multirow{2}{*}{$\begin{array}{l}0.011 * \\
-\end{array}$} \\
\hline & am) & 0.260 & $0.011 *$ & \\
\hline & $\begin{array}{l}\text { Post-Stress }(14: 00- \\
15: 00 \mathrm{pm})\end{array}$ & & & \\
\hline
\end{tabular}

*The statistical is significance is marked with asterisks $p<0.0001 * * ; p<0.001 * * ; p<0.05 *$ 
Figures
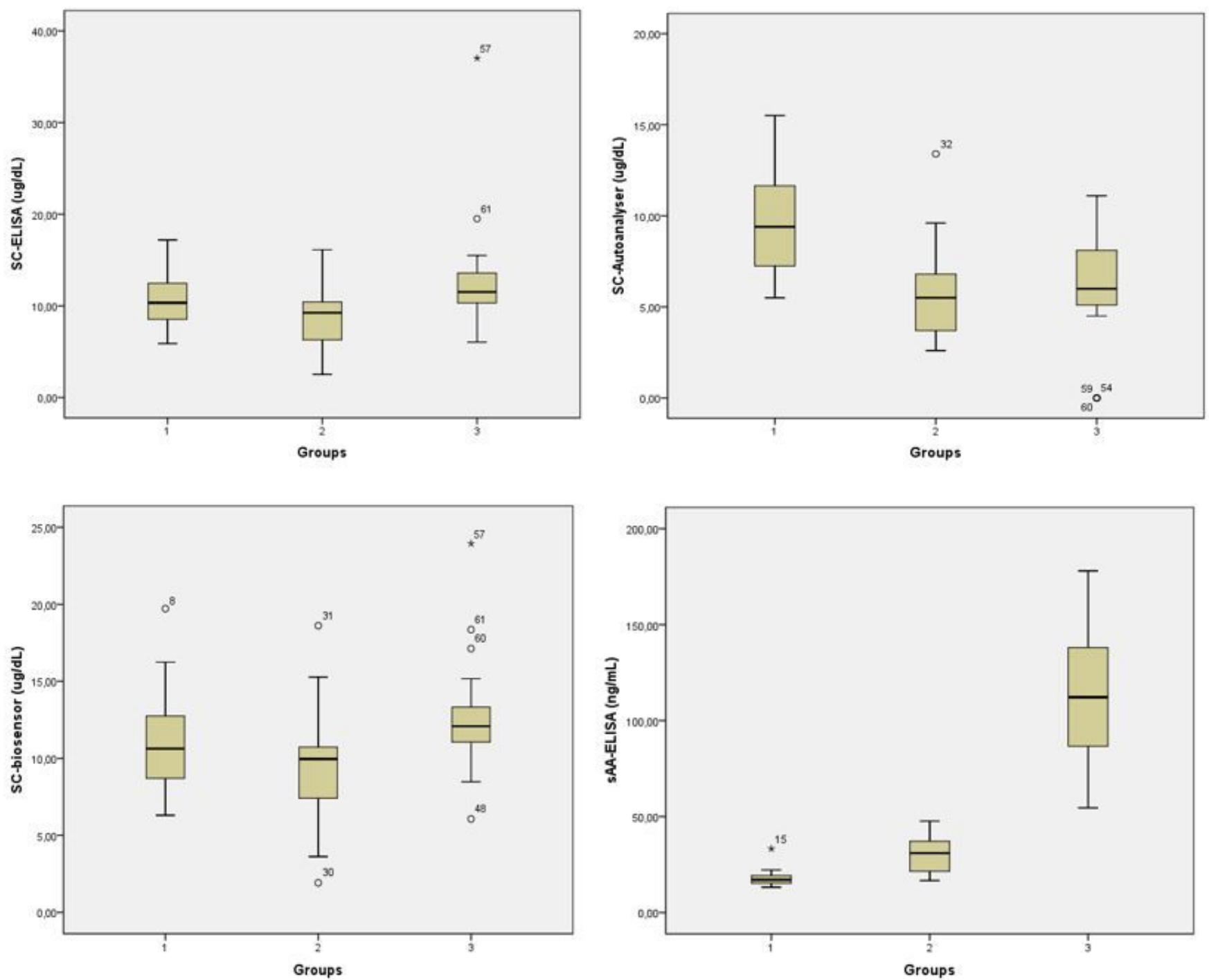

Group 1: 08.00-09.00 (morning); Group 2: Before exam (pre-stress); Group 3:After unaware exam (post-stress)

\section{Figure 1}

Performance of methods used to determine cortisol and amylase levels in samples taken at different times Group 1: 08.00-09.00 (morning); Group 2: Before exam (pre-stress); Group 3:After unaware exam (post-stress) 


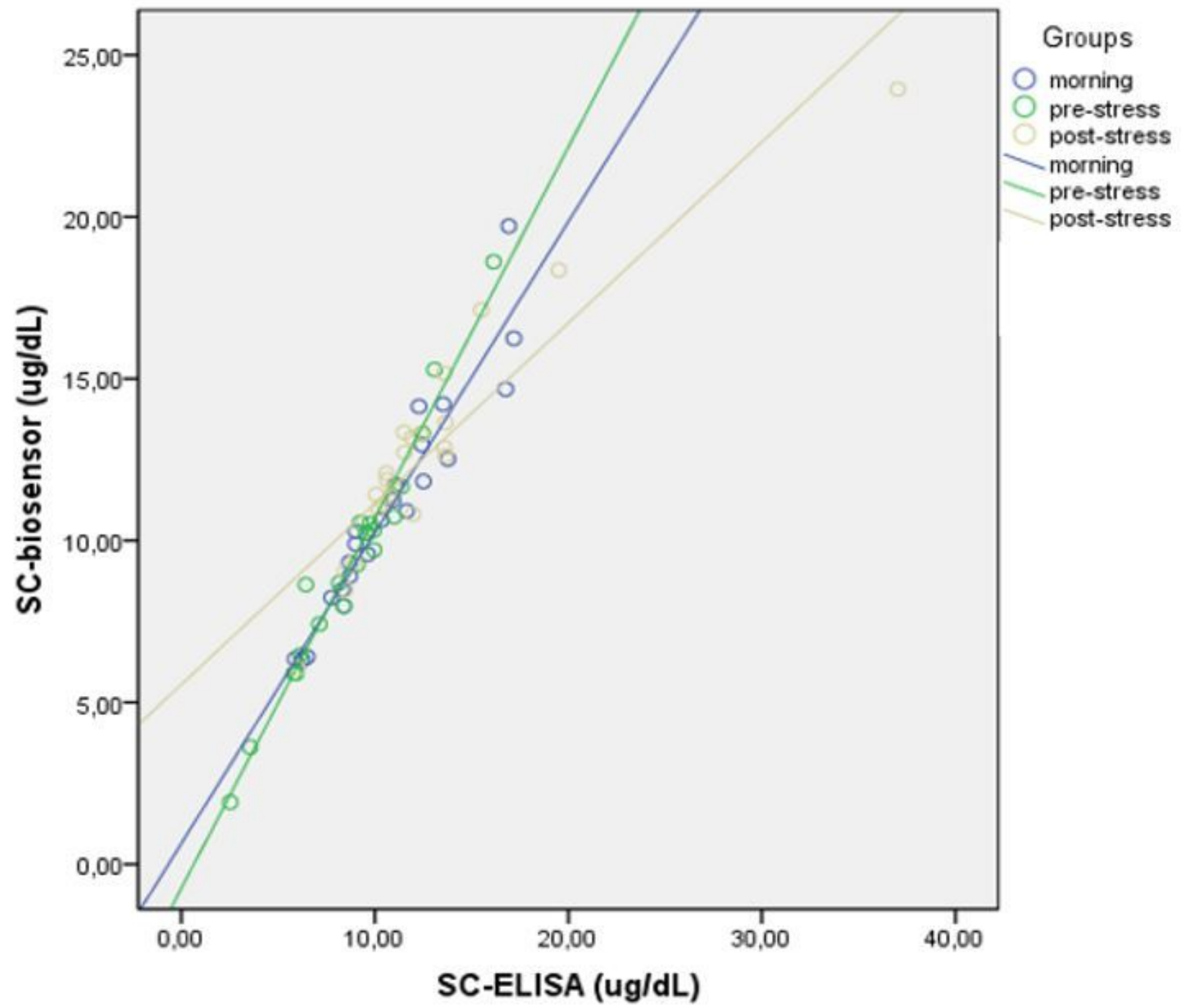

Figure 2

Correlation of SC-ELISA and SC-Biosensor methods 


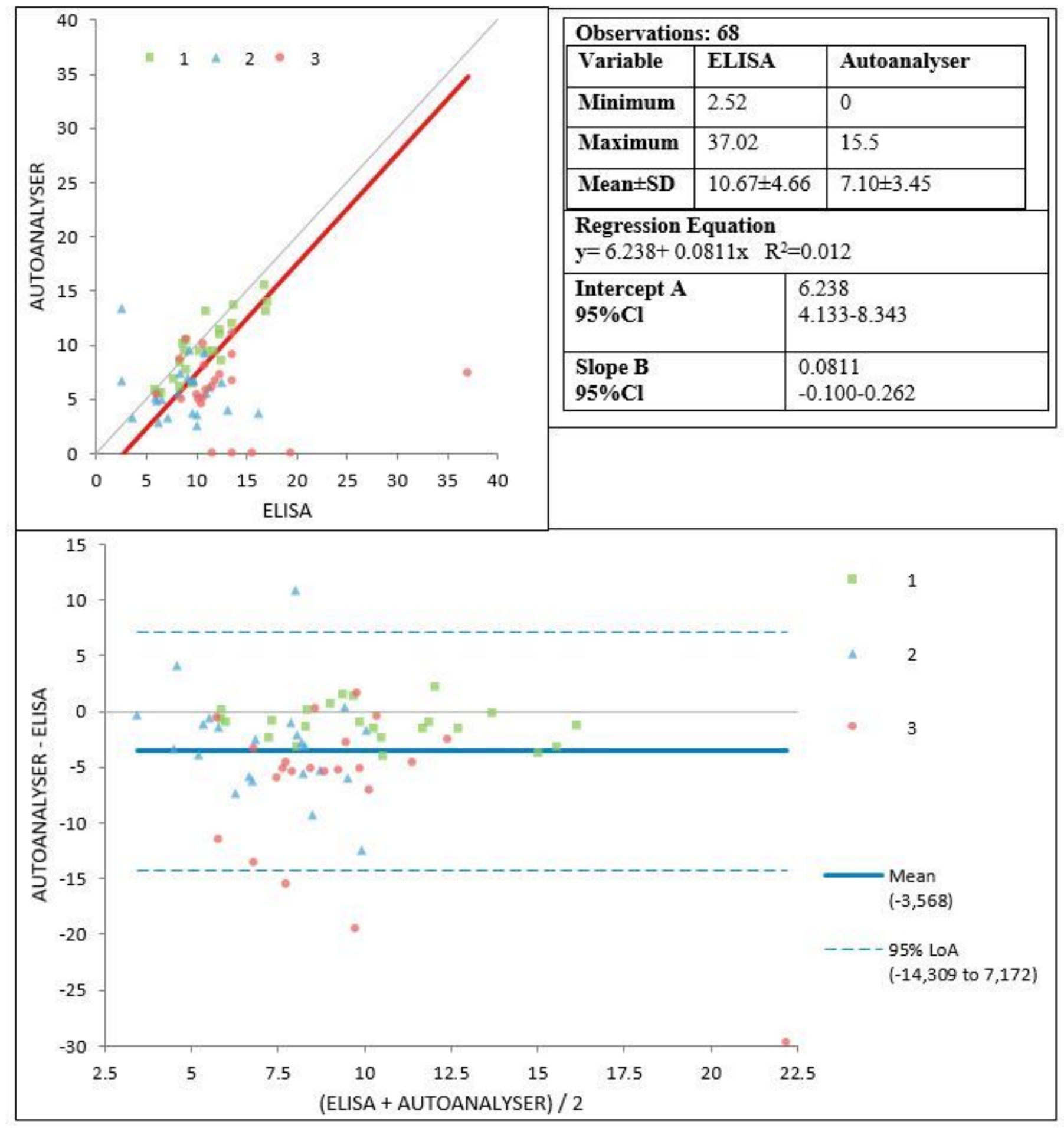

Figure 3

a) Distribution of cortisol results between ELISA method and Autoanalyser method b) Numerical values of the distribution of cortisol results c) Bland-Altman plot of cortisol results between ELISA method and Autoanalyser method Figure 3: a) Distribution of cortisol results between ELISA method and Autoanalyser method b) Numerical values of the distribution of cortisol results c) Bland-Altman plot of cortisol results between ELISA method and Autoanalyser method (Green: 08.00-09.00 (morning); Blue: before exam (prestress); Pink: unaware exam (post stress) 


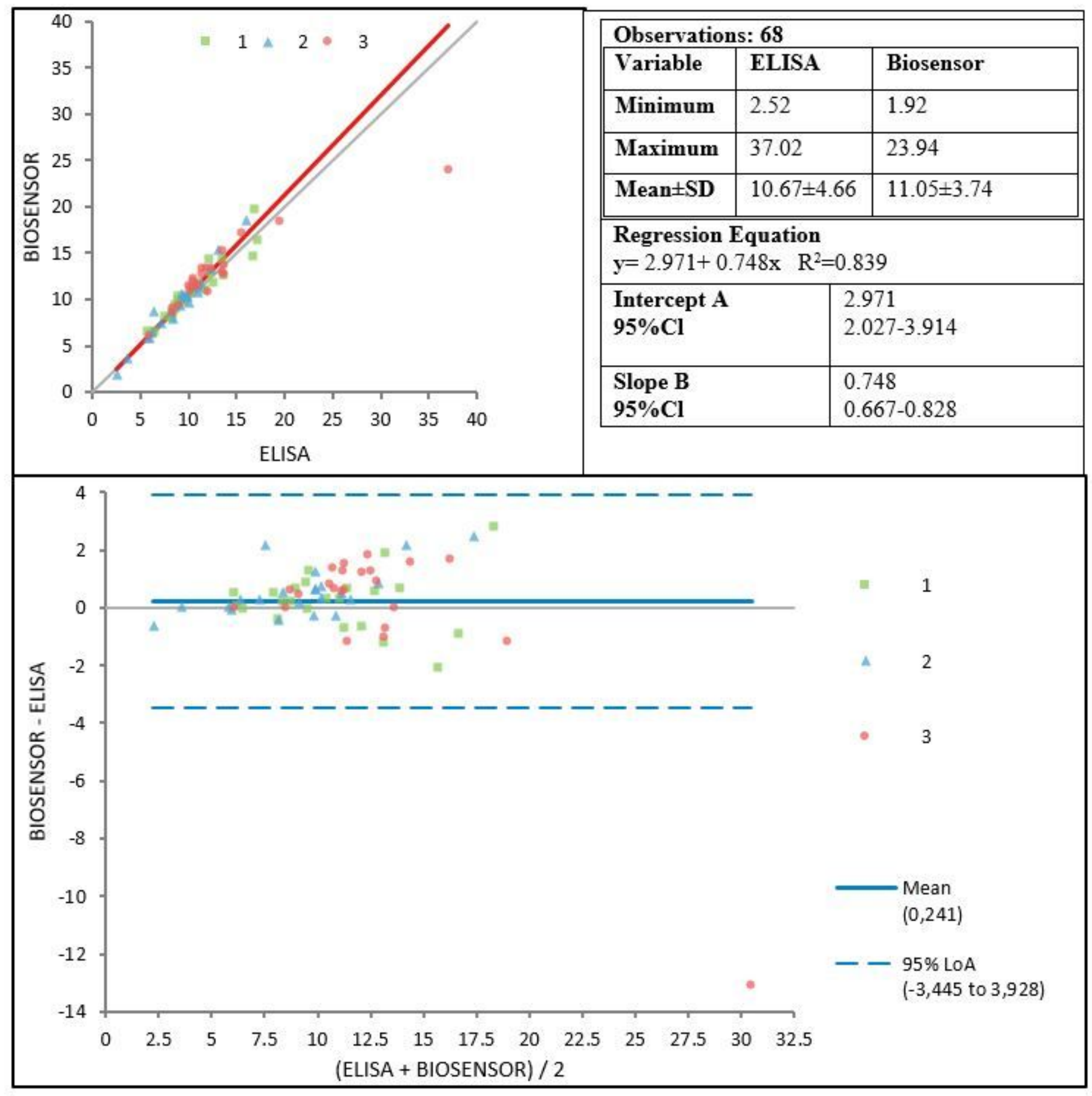

Figure 4

a) Distribution of cortisol results between ELISA method and Biosensor method b) Numerical values of the distribution of cortisol results $\mathrm{c}$ ) Bland-Altman plot of cortisol results between ELISA method and Biosensor method Figure 4 a) Distribution of cortisol results between ELISA method and Biosensor method b) Numerical values of the distribution of cortisol results c) Bland-Altman plot of cortisol results between ELISA method and Biosensor method (Green: 08.00-09.00 (morning); Blue: before exam (prestress); Pink: unaware exam (post stress) 


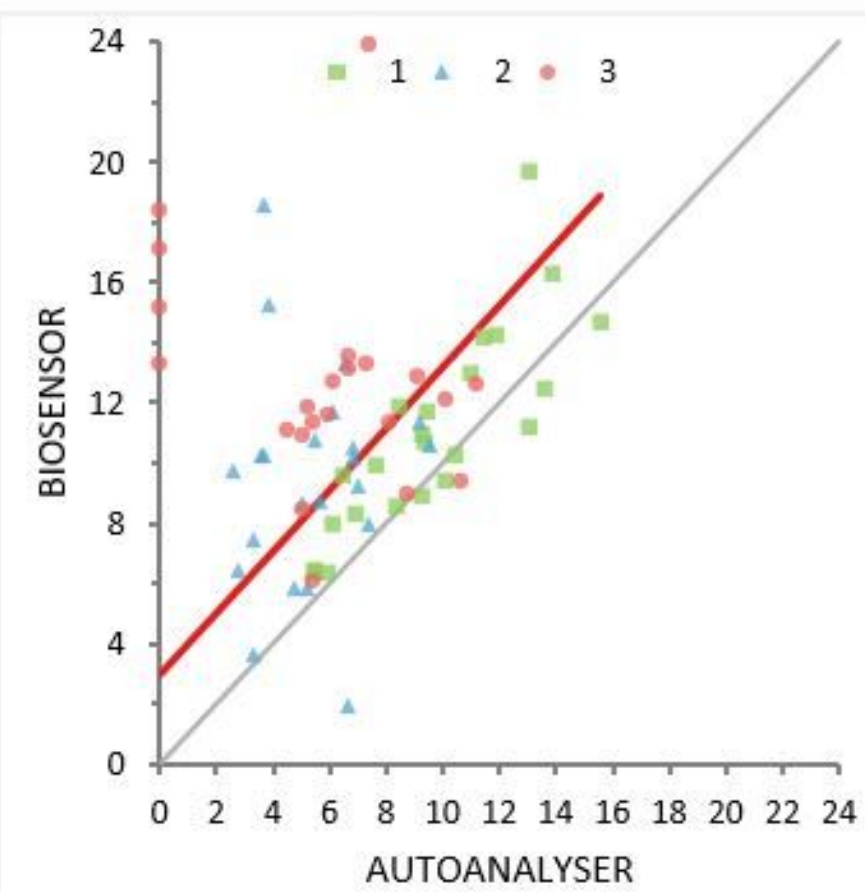

\begin{tabular}{|c|c|c|c|}
\hline \multicolumn{4}{|c|}{ Observations: 68} \\
\hline Variable & \multicolumn{2}{|c|}{ Autoanalyser } & Biosensor \\
\hline Minimum & \multicolumn{2}{|l|}{0} & 1.92 \\
\hline Maximum & \multicolumn{2}{|l|}{15.5} & 23.94 \\
\hline Mean \pm SD & \multicolumn{2}{|l|}{$7.10 \pm 3.45$} & $11.05 \pm 3.74$ \\
\hline \multicolumn{4}{|c|}{$\begin{array}{l}\text { Regression Equation } \\
\mathbf{y}=9.983+0.153 \times \mathrm{R}^{2}=0.019\end{array}$} \\
\hline \multicolumn{2}{|l|}{$\begin{array}{l}\text { Intercept A } \\
95 \% \mathrm{Cl}\end{array}$} & \multicolumn{2}{|c|}{$\begin{array}{l}9.983 \\
7.877-12.09\end{array}$} \\
\hline \multicolumn{2}{|l|}{$\begin{array}{l}\text { Slope B } \\
95 \% \mathrm{Cl}\end{array}$} & \multicolumn{2}{|c|}{$\begin{array}{l}0.153 \\
-0.118-0.424\end{array}$} \\
\hline
\end{tabular}

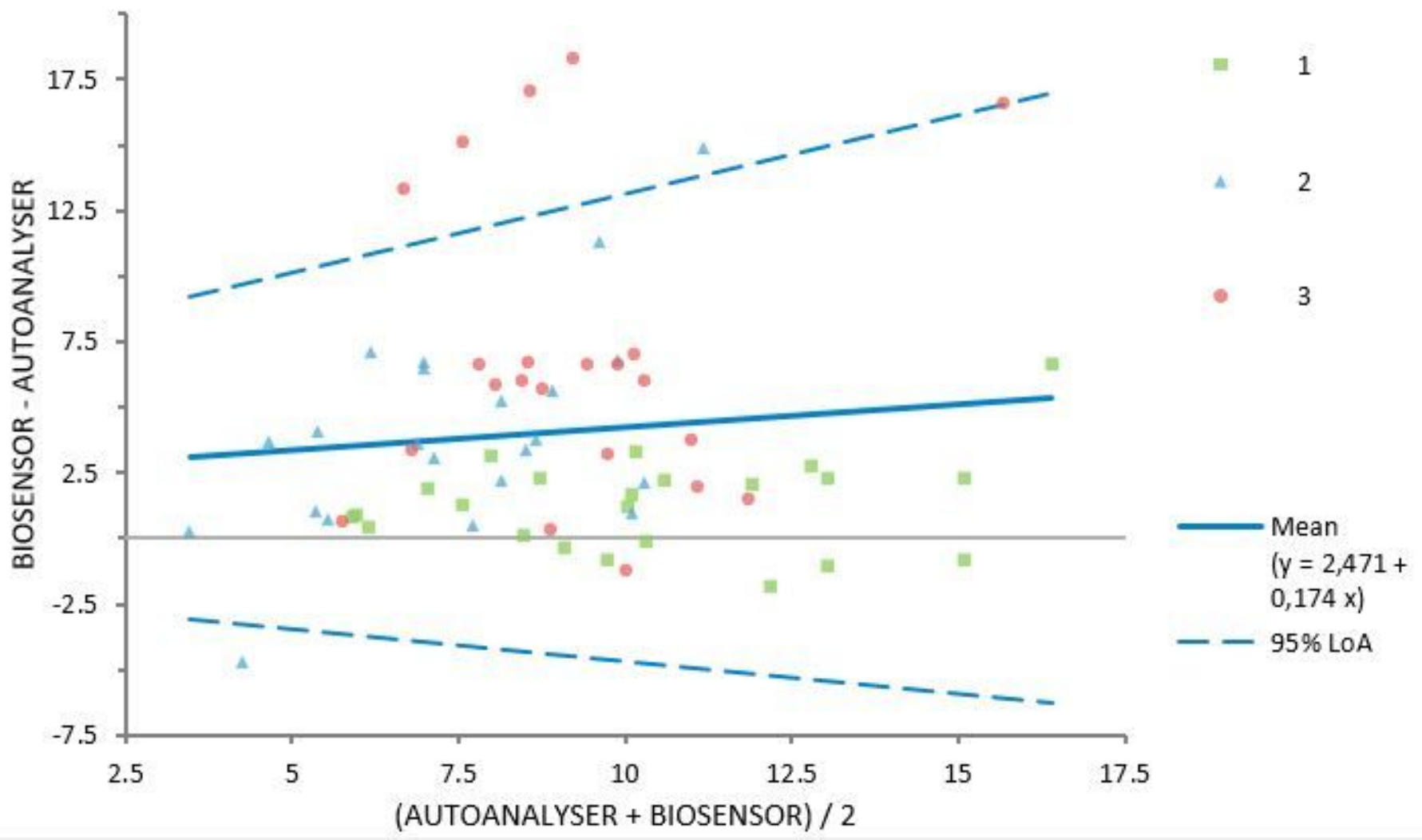

\section{Figure 5}

a) Distribution of cortisol results between Autoanalyser method and Biosensor method b) Numerical values of the distribution of cortisol results $\mathrm{c}$ ) Bland-Altman plot of cortisol results between Autoanalyser method and Biosensor method Figure 5 a) Distribution of cortisol results between Autoanalyser method and Biosensor method b) Numerical values of the distribution of cortisol results c) Bland-Altman plot of cortisol results between Autoanalyser method and Biosensor method 